\title{
ESTRATÉGIAS DE SOBREVIVÊNCIA DE ESPÉCIES ARBÓREAS EM AMBIENTES DEFICIENTES POR FÓSFORO NA AMAZÔNIA
}

\author{
P. C. de Oliveira ${ }^{1}$, C. J. R. de Carvalho ${ }^{2}$ \\ ${ }^{1}$ Universidade Federal do Oeste do Pará- UFOPA, Coordenadora do Laboratório de \\ Estudos de Ecossistemas Amazônicos- LEEA \\ pchaves@ufpa.br \\ ${ }^{2}$ Empresa Brasileira de Pesquisas Agropecuária - EMBRAPA-CPATU \\ carvalho@cpatu.embrapa.gov.br
}

Artigo submetido em agosto/2010 e aceito em março/2011

\begin{abstract}
RESUMO
As florestas secundárias (capoeiras) situadas no Nordeste do Estado do Pará, geralmente utilizadas pela agricultura itinerante, onde fases de regeneração da vegetação intercalam-se com fases de cultivo agrícola caracterizam-se pela baixa fertilidade dos solos, refletida entre outros fatores pelas reduzidas concentrações de fósforo $(\mathrm{P})$ disponível. Contudo, algumas espécies arbóreas comuns nestas florestas como Neea macrophylla e Cecropia palmata desenvolvem estratégias no particionamento de fósforo que permitem o acúmulo em potencial do nutriente em seus tecidos foliares, que utilizados como mulch, pode tornar-se uma alternativa de incremento do fósforo orgânico em Sistemas Agroflorestais locais. Embora os estoques de fósforo, possam chegar até 2 e $3 \mathrm{~kg}$ de fósforo em folhas e lenhos por árvore de Neea macrophylla, a Eficiência de Utilização de $\mathrm{P}$ pelas espécies potencialmente acumuladoras de fósforo foi muito baixa, demonstrando ser este um mecanismo de tolerância à solos deficientes em fósforo.
\end{abstract}

PALAVRAS-CHAVE: Fósforo, Amazonia, particionamento.

\section{STRATEGIES OF SURVIVAL FOR WOOD SPECIES IN DEFICIENT ENVIRONMENTS FOR PHOSPHORUS IN THE AMAZON}

\begin{abstract}
The secondary forests (capoeiras) situated in the Northeast of Pará, generally used for shift agriculture, where phases of regeneration are intercalated with agricultural culture, are characterized currently for low soil fertility among others reflected factors for the reduced concentrations of available phosphorus (P). However, some common species in these forests as Neea macrophylla and Cecropia palmata develop strategies in the partition of $\mathrm{P}$ that allow the accumulation in potential of the nutrient in its leaves tissues, suggesting a rich mulch in $\mathrm{P}$, which can become an alternative of $\mathrm{P}$ organic increment in local Agroforests Systems. Although the stock of $\mathrm{P}$, can arrive up to 2 and $3 \mathrm{~kg}$ of $\mathrm{P}$ in leaves and primary stems for tree of Neea macrophylla, the P Use Efficiency for the potentially accumulative species were very low, demonstrating to be a mechanism of tolerance to environments with $\mathrm{P}$ deficit.
\end{abstract}

KEY-WORDS : Phosphorus, Amazon, nutrient partition. 


\section{ESTRATÉGIAS DE SOBREVIVÊNCIA DE ESPÉCIES ARBÓREAS EM AMBIENTES DEFICIENTES POR FÓSFORO NA AMAZÔNIA}

\section{INTRODUÇÃO}

O fósforo $(\mathrm{P})$ como um dos macronutrientes fundamentais na nutrição das plantas juntamente com o nitrogênio $(\mathrm{N})$ quando em déficit no solo pode limitar a produção da maioria das culturas (Vance, 2001). Algumas florestas secundárias no Nordeste do Estado do Pará sucessivamente substituídas com cultivos agrícolas sob um sistema de preparo de área com o uso do fogo típico na Região evoluíram ao longo do tempo para florestas sob solos com baixa fertilidade onde os reduzidos níveis de $\mathrm{P}$ disponíveis às plantas provoca um estresse nutricional que acaba por expressar uma flora local onde estratégias de particionamento de $\mathrm{P}$ devem determinar a permanência ou não das espécies ao longo dos anos.

A caracterização das concentrações de $\mathrm{P}$ nos tecidos vegetais é fundamental na compreensão da dinâmica deste elemento, mas sobretudo na identificação de recursos vegetais potencialmente acumuladores de $\mathrm{P}$, onde parâmetros como o Teor, o Estoque e a Eficiência de Utilização de $\mathrm{P}$ podem expressar perfis diferentes para uma mesma problemática.

$\mathrm{O}$ teor de $\mathrm{P}$ nos tecidos vegetais ( $\mathrm{mg} \mathrm{P}^{-1}$ Matéria Seca) varia espacialmente e temporalmente, isto é: entre os diferentes órgãos das plantas e ao longo do ciclo de vida delas. $\mathrm{O}$ estoque de $\mathrm{P}$, por sua vez, representado pela quantidade de $\mathrm{P}$ contido na biomassa produzida pode também ser outra medida quantitativa do status de $\mathrm{P}$ nas plantas, porém com pouca plasticidade, pois a produção de biomassa varia ao longo do ciclo de vida das espécies e a partir de Interações Biofísicas específicas traduzidas em respostas ecofisiológicas próprias dentro de um determinado contexto climático.

Dessa forma, a Eficiência de Utilização de Nutrientes no caso de P (EUP) um índice proposto por Siddiqui \& Glass (1981), expresso pela razão entre a matéria seca total e a concentração do nutriente no tecido, talvez melhor expresse qualitativamente o potencial das espécies em tolerar condições de déficit. Plantas eficientes na utilização de $\mathrm{P}$ em ambientes com déficit serão então àquelas que obtiverem boa produção de matéria seca com baixas concentrações de $\mathrm{P}$ no tecido considerado. Como tática de tolerância e, por conseguinte de sobrevivência das espécies em solos com baixas concentrações de $\mathrm{P}$ torna-se um fato importante $\mathrm{o}$ acompanhamento dessas eficiências ao longo do tempo para a caracterização da evolução da fisiologia vegetal onde a adaptação ou não de determinadas espécies à situações de estresse poderá ser observada.

Contudo, a variação na alocação do $\mathrm{P}$ dentro da planta, bem como a sua remobilização entre os diferentes órgãos são estratégias que as espécies vegetais desenvolvem quando fatores extrínsecos ou intrínsecos a elas determinam situações de déficit ou não do elemento. Em condições de bom suprimento de fósforo, o Pi (fósforo inorgânico) absorvido pelas raízes é transportado no xilema até as folhas novas e retranslocado do floema para folhas velhas e ramos em crescimento, assim como dos caules para as raízes. Contudo, em condições de estresse, o suprimento de Pi é restrito nos caules, oriundo das raízes via xilema, sendo acumulado em folhas mais velhas e depois retranslocado para folhas novas e raízes em crescimento (Mimura et al, 1996). Para isso, ocorre uma redução nos estoques de Pi associado à quebra de $\mathrm{P}$ orgânico nas folhas mais velhas. Porém, um fato curioso para o autor são as altas concentrações de $\mathrm{P}$ orgânico no floema de plantas sob déficit de $\mathrm{P}$, o qual ele atribui à presença de genes mutantes. É de se esperar portanto, que nas espécies de vegetações secundárias onde os baixos níveis de $\mathrm{P}$ são determinantes, o acúmulo de $\mathrm{P}$ em caules e folhas mais velhas. 
De acordo com Cherbuy et al (2001), 25\% de P das folhas de Quercus ilex foram removidos ao longo da primavera e um decréscimo de $5 \%$ da biomassa foliar média foi observado, confirmando a hipótese de que em vegetação sempre-verde, as folhas exercem papel importante na remobilização de recursos a fim de garantir os processos de desenvolvimento, onde as relações de fonte e dreno variam com o tempo assim como o estoque de nutrientes. Em espécies potencialmente acumuladoras de $\mathrm{P}$ em vegetações secundárias no Nordeste Paraense que também na sua maioria são sempre-verdes, as folhas mais velhas, seguindo a mesma lógica também deveriam remobilizar P para flores e frutos mesmo em condições de baixa sazonalidade?

A remobilização de $\mathrm{P}$ entre folhas maduras (funcionais) e em senescência de 24 espécies arbóreas de florestas secundárias no Nordeste Paraense foi estudada por Oliveira et al (2002) e os resultados mostraram que na espécie que mais acumulou P (3,8 mg.g-1 M.S.) Neea macrophylla, pouca reabsorção foi observada, sugerindo que neste caso, o ambiente saiu ganhando através do acúmulo do $\mathrm{P}$ no litter desta espécie. Contudo, as demais espécies tenderam a reabsorver entre 50-70 \% do $\mathrm{P}$ a partir das folhas fisiologicamente maduras, uma remobilização que caracteriza uma estratégia de economia de $\mathrm{P}$ em ambientes com déficit.

$\mathrm{O}$ estoque de $\mathrm{P}$ entre os diferentes órgãos da planta quando este está em excesso, segundo Parks et al (2000) é preferencialmente o caule , o qual armazenou entre 0.5 e $1.5 \mathrm{~g} \mathrm{P} / \mathrm{Kg}$ na Matéria Seca em Banksia ericifolia L., enquanto as folhas maduras, de 0.5 a 0.8 g P/ Kg M.S. Tais resultados sugerem segundo o autor, que o caule deve ser um índice de determinação do status de $\mathrm{P}$ melhor que as folhas. Contudo, numa situação oposta, onde o P estivesse em déficit, como nos solos sob as vegetações secundárias do Nordeste Paraense, o caule ainda funcionaria como um índice melhor do que as folhas ? Neste contexto a remobilização do P entre folhas, caules, flores e frutos, frente a uma situação de estresse permanente é fator determinante na economia deste nutriente para a planta.

Segundo Smith e Shortle (2001), existe certo controle na conservação das concentrações dos elementos no xilema, o que pode ser observado quando comparado os dados da composição química do fluxo xilemático obtido via câmara de pressão de Scholander e a prévia composição química do solo, sugerindo alto grau de controle homeostático dos nutrientes. Dessa forma, as variações abióticas como por exemplo a disponibilidade de P no solo para as plantas, poderá exercer um reflexo na concentração de $\mathrm{P}$ no xilema, a fim de manter a homeostase no sistema solo-planta. Esta estratégia é fundamental em ambientes com déficit do nutriente e determinante na nutrição das plantas.

Fatores extrínsecos às espécies acentuam as variações nos teores de $\mathrm{P}$ nos tecidos, como por exemplo, a difusão do P no solo principal mecanismo de absorção. Logo, o teor de água no solo, compactação, micorrizas e temperatura podem influenciar os processos difusivos de $\mathrm{P}$ e, por conseguinte os teores nas plantas. Outra variável, o fator capacidade de $\mathrm{P}(\mathrm{FCP})$ dos solos, que é função do fator intensidade (I) de $\mathrm{P}$, representado pelo $\mathrm{P}$ da solução do solo e do fator quantidade (Q), fósforo adsorvido também exerce influência na dinâmica do fósforo do solo para a planta. Dependendo das características físico-químicas dos solos o $\mathrm{FCP}(\mathrm{Q} / \mathrm{I})$ poderá ser maior ou menor. As concentrações críticas de P na solução do solo variam com o FCP dos solos entre 0,05 mg. $\mathrm{l}^{-1}-0,2 \mathrm{mg} . \mathrm{l}^{-1}$, dessa forma, solos argilosos tropicais intemperizados geralmente com baixa FCP possuem concentração crítica de P referente ao maior valor acima citado.

A concentração de alumínio e nitrogênio nos solos é outro fator que influencia na absorção e distribuição de $\mathrm{P}$, pois de acordo com Bengtsson et al (1994) uma concentração igual a $0.1 \mathrm{mM}$ de $\mathrm{Al}$ promoveu o aumento nas concentrações de $\mathrm{P}$ nas raízes e caules, enquanto que $1.0 \mathrm{mM}$ Al reduziu drasticamente tais concentrações em Fagus sylvatica. Considerando que 
os solos das vegetações secundárias do Nordeste paraense apresentam valores superiores a 0.1 $\mathrm{mM} \mathrm{Al}$ as espécies estudadas tolerantes a baixos níveis de $\mathrm{P}$ sentirão tal influência dos níveis de alumínio sobre os teores de $\mathrm{P}$ nos caules e raízes?

A presença de nitrato por sua vez em altas concentrações assim como o alumínio, também reduziu as concentrações de $\mathrm{P}$ nas raízes, caules e folhas de $F$. sylvatica. Sob este ponto de vista, a adubação nitrogenada, sobretudo na forma de nitrato $\left(\mathrm{NO}_{3}{ }^{-}\right)$praticada por pequenos agricultores na fase inicial do ciclo de vida da cultura deve ser monitorada em função desta possível correlação negativa com a absorção de $\mathrm{P}$, haja vista, a condição de déficit deste elemento nos solos agrícolas das vegetações secundárias estudadas.

A idade fisiológica das plantas parece não influenciar nas concentrações foliares de $\mathrm{P}$ como observaram Johnson et al (2001), quando compararam florestas secundárias com 10, 20 e 40 anos na região Bragantina do Estado do Pará. Contudo, capoeiras mais novas com 2 a 3 anos ainda precisam ser estudadas sob este mesmo aspecto. Se um século de agricultura itinerante ainda não provocou limitações nutricionais para a regeneração da vegetação certamente deve alterar o metabolismo de captação de nutrientes como forma de manter a sustentabilidade do sistema.

Este trabalho teve por objetivo prospectar e identificar os recursos vegetais arbóreos potencialmente acumuladores de $\mathrm{P}$ comuns em florestas secundárias com baixos níveis deste elemento nos solos, a fim de caracterizar de forma quantitativa e qualitativa o nutriente pelos diferentes compartimentos (folhas, cascas e lenhos) através da determinação do Teor, Estoque e Eficiência de Utilização de P (EUP). A partir dessa caracterização, identificar quais os melhores parâmetros para selecionar espécies tolerantes a ambientes com estresse de $\mathrm{P}$ isto é, espécies EMERGENTES numa realidade edafo-climática adversa com tendência a insustentabilidade ao longo do tempo caso não haja mudanças no manejo dos solos agriculturáveis.

\section{METODOLOGIAS}

A pesquisa se desenvolveu em floresta secundária com cinco anos de regeneração no Município de Igarapé-Açú no estado do Pará. Foram selecionadas três espécies, sendo duas acumuladoras de fósforo (P), Neea macrophylla e Cecropia palmata, e uma não acumuladora, Casearia arborea. Foram marcadas 10 árvores por espécie. A seguir, foram retiradas subamostras de folhas, cascas e lenhos da porção basal, mediana e apical dos caules primários das três espécies para determinação dos teores de $\mathrm{P}$ total através do método proposto por Murphy \& Riley (1962) através das seguintes etapas:

1. Digestão da matéria seca com $2 \mathrm{ml}$ de Ácido Sulfúrico

2. Adição de $3 \mathrm{ml}$ de Peridrol $30 \%$

3. Utilização de uma alíquota de $5 \mathrm{ml}$ da amostra e adição de 2 ug de Nitrofenol.

4. Adição de $2 \mathrm{ml}$ de Hidróxido de Sódio ( $\mathrm{Na} \mathrm{OH})$

5. Titulação com Acido Sulfúrico 0,25 M (H2SO4)

6. Leitura da absorbância à $885 \mathrm{~nm}$. 
A determinação dos estoques (E) de $\mathrm{P}$ total nos tecidos foliares, cascas e lenhos da porção basal, mediana e apical foram obtidos através da relação $E=T e o r P\left(\mathrm{~g} \mathrm{~kg}^{-1}\right) X \mathrm{M}$. S. (kg), onde este parâmetro associado ao Teor de $\mathrm{P}$ é considerado de caráter puramente quantitativo. Contudo, a Eficiência de Utilização de Nutrientes (EUN), no caso de P (EUP) um parâmetro qualitativo, foi obtida a partir do modelo proposto por Sidiqqui \& Glass (1981), onde EUP= M.S Teor $\mathrm{P}^{-1}$ no tecido.

Foram feitas a Estatística Descritiva e posteriormente aplicado o Teste t para a comparação entre as médias dos teores, estoques e Eficiência de Utilização de $\mathrm{P}$ das 3 espécies estudadas, Neea macrophylla, Cecropia palmata e Casearia arborea em cada um dos 7 compartimentos (folhas, cascas e lenhos da base, do meio e do ápice dos caules primários). Foi realizada ainda a Análise de Variância para a Eficiência de Utilização de P nas três espécies estudadas.

Quanto à variação do $\mathrm{N}^{-\mathrm{NH}_{4}}$ (Bremner and Mulvaney 1982) esta foi determinada através das seguintes etapas:

1. Digestão da matéria seca com $3 \mathrm{ml}$ de Ácido Sulfúrico (H2SO4)

2. Utilização de $0,5 \mathrm{ml}$ da amostra e adição de mistura catalisadora.

3. Titulação com Hidróxido de Sódio 0,5M e adição de $1 \mathrm{ml}$ de EDTA.

4. Leitura da absorbância a $667 \mathrm{~nm}$.

Os dados relativos ao N-NH4 foram estudados através de Análise Multivariada a partir da aplicação do Teste de Hotteling. O programa estatístico utilizado foi o BioEstat 3.0 (Ayres et al, 2003).

\section{RESULTADOS \& DISCUSSÕES}

Os resultados relativos ao particionamento de $\mathrm{P}$ em árvores de Neea macrophylla, Cecropia palmata e Casearia arborea demonstraram que os teores de $\mathrm{P}_{\text {total }}$ obtidos nos tecidos foliares das espécies Neea macrophylla e Cecropia palmata não diferiram significativamente conforme o Teste t. As concentrações encontradas $(1.3$ e $1.6 \mathrm{~g}$ P/kg na matéria seca, respectivamente para folhas verdes de Neea macrophylla e Cecropia palmata) expressam um teor de $\mathrm{P}$ superior ao padrão encontrado nas plantas nativas da Região, comumente abaixo de $1.0 \mathrm{~g} \mathrm{P} / \mathrm{kg}$. Contudo, há de se registrar que uma amplitude muito grande foi observada nas amostras foliares de Neea macrophylla, pois outliers de até 3.69 g P/kg M.S. (FIGURA 1) foram encontrados em árvores jovens, sinalizando que estádios iniciais de crescimento mobilizam muito mais $\mathrm{P}$ para os tecidos foliares do que são capazes árvores adultas em estádios de desenvolvimento nas quais a floração e frutificação tendem a competir pelo mesmo recurso. Sendo assim, a utilização de biomassa foliar dessas espécies como mulch em Sistemas Agroflorestais (SAFs) onde exista deficiência de $\mathrm{P}$ nos solos pode vir a ser uma alternativa na recuperação dos níveis deste mineral em ambientes como os da Agricultura Itinerante onde o fogo alternado a curtos períodos de regeneração das vegetações secundárias mostra-se incapaz de promover o aumento dos níveis de $\mathrm{P}$. 


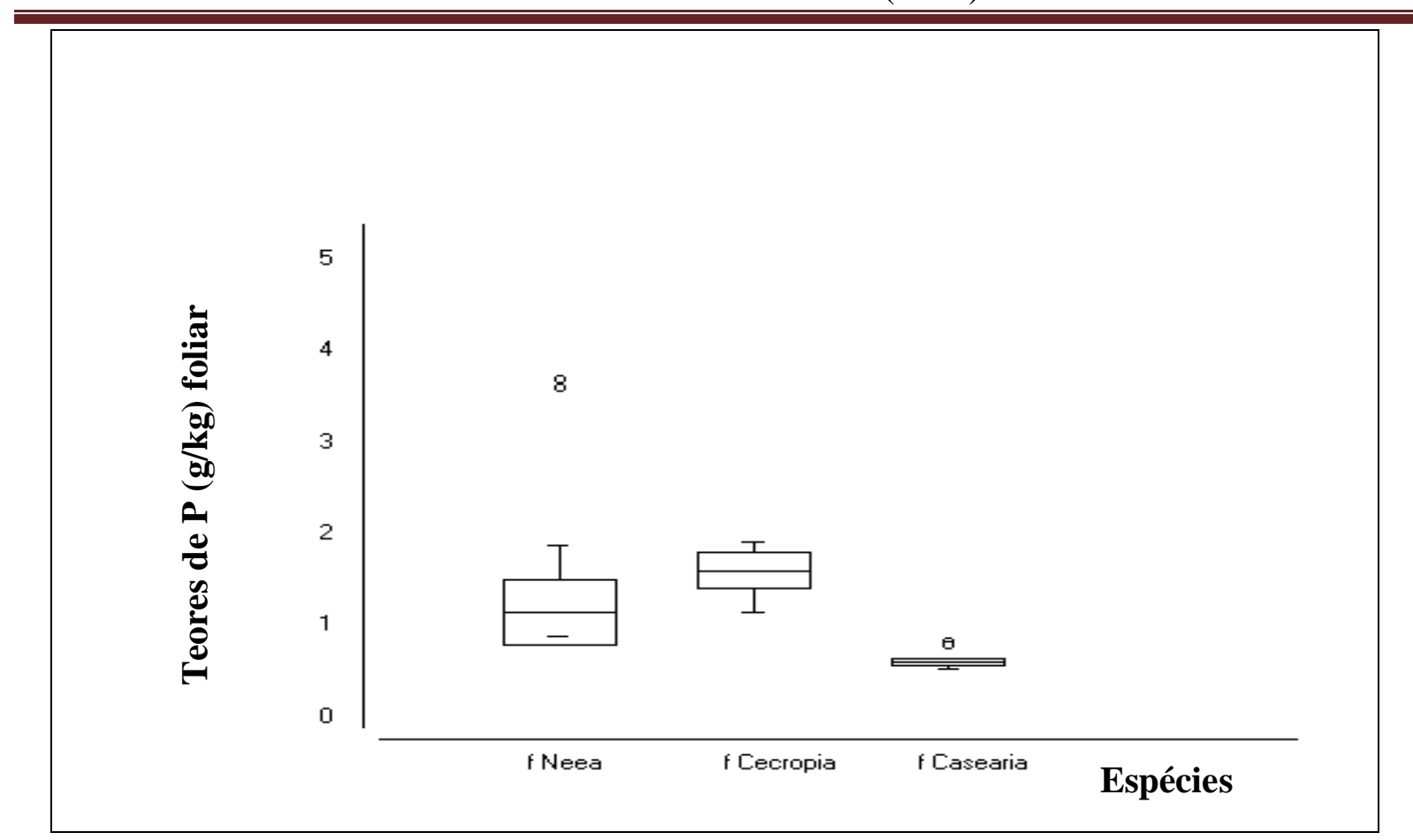

FIGURA 1 - Teores de $\mathrm{P}(\mathrm{g} / \mathrm{kg}$ na matéria seca) em tecidos foliares (f) de Neea macrophylla (a), Cecropia palmata(a) e Casearia arborea(b) com respectivos desvios padrões (box plot) e máximo e mínimos (suíças). * diferentes letras dentro dos parênteses representam diferença estatística.

A diferença altamente significativa entre os teores de $\mathrm{P}$ em folhas de Neea macrophylla $e$ Casearia arborea e entre Cecropia palmata e Casearia arborea corrobora o potencial de Neea e Cecropia em acumular $\mathrm{P}$ nestes tecidos e de poderem ser utilizadas como componentes ecológicos de Sistemas Agroflorestais ou durante o processo de Enriquecimento da capoeira no contexto da Agricultura Itinerante a fim de promover a sustentabilidade de ecossistemas produtivos a partir de incrementos no nível de $\mathrm{P}$ orgânico. Considerando que o metabolismo foliar pode ser constrangido por deficiências de $\mathrm{P}$ nos solos expressas na respiração noturna, na área e no peso foliar de acordo com Meir, Grace e Miranda (2001) estarão o metabolismo foliar de Neea, Cecropia e Casearia sob constrangimento? 
Quando observamos um novo compartimento como as cascas dos caules primários das 3 espécies estudadas quanto ao teor de $\mathrm{P}$, os resultados demonstraram que a dinâmica do fluxo de $\mathrm{P}$ acaba por determinar valores crescentes nos Teores de $\mathrm{P}$ da porção basal para a porção apical das cascas do caule, sendo que Cecropia palmata foi a espécie que mais acumulou P no ápice do que demais espécies conforme FIGURA 2.

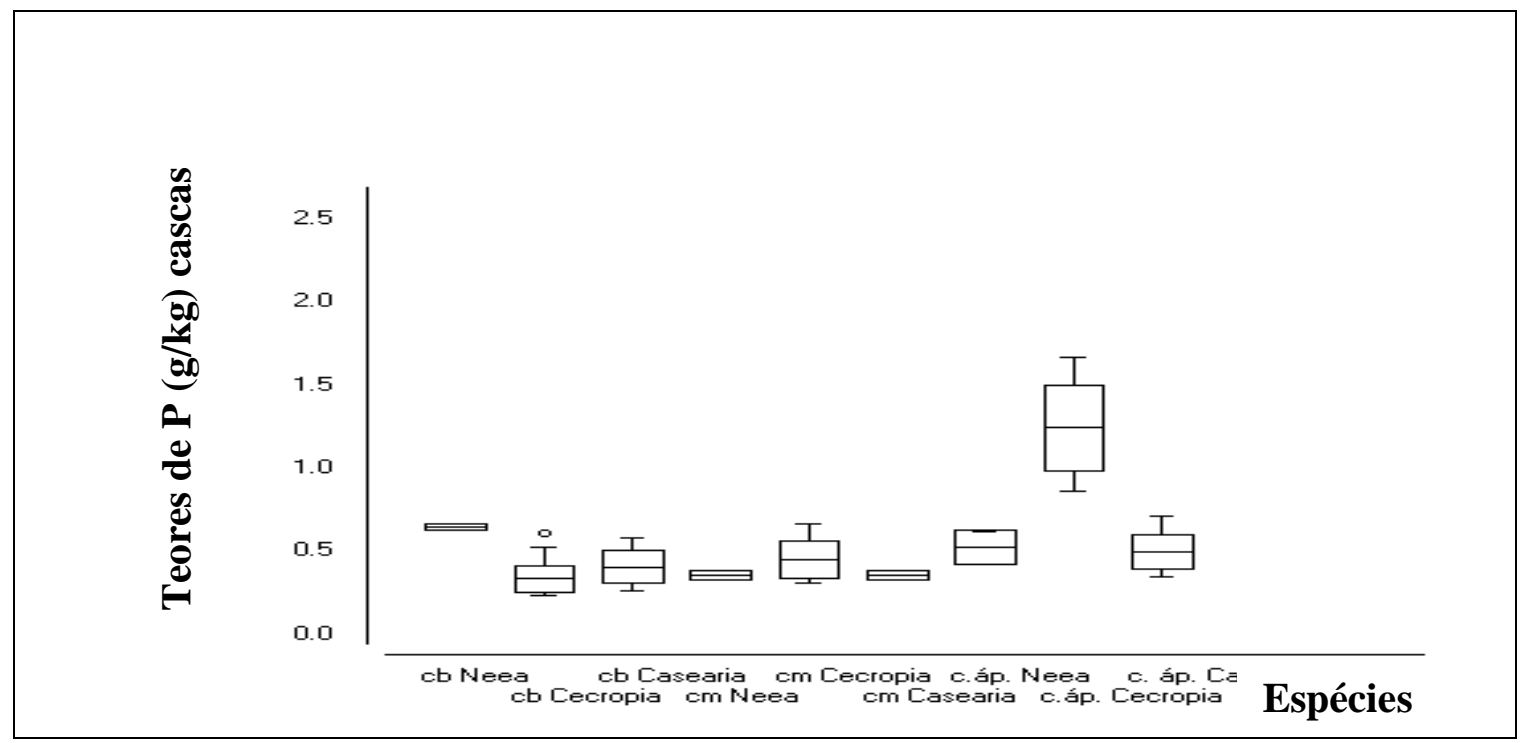

FIGURA 2 - Teores de $\mathrm{P}$ (g/kg na matéria seca) em cascas das porções basal (cb), mediana (cm) e apical (c.áp.) dos caules primários de Neea macrophylla, Cecropia palmata e Casearia arborea com respectivos desvios padrões (box plot) e máximos e mínimos (suíças). * apenas entre as cascas da base dos caules de Cecropia e Casearia e do ápice de Neea e Casearia não houve diferenças significativas.

Estes resultados sugerem que regiões meristemáticas de Cecropia palmata podem estar mobilizando concentrações elevadas de $\mathrm{P}$ tal como as folhas, o que poderá propiciar crescimento primário superior ao de Neea macrophylla e Casearia arborea, sugerindo que Cecropia palmata em condições de estresse por P consegue de certa forma garantir condições propícias ao crescimento vertical, enquanto Neea macrophylla tende a reduzir o acúmulo de $\mathrm{P}$ nas cascas da porção apical propiciando condições não tão favoráveis ao crescimento primário. Certamente estudos complementares de Análise de Crescimento são necessários.

Quanto às concentrações de $\mathrm{P}$ nos lenhos das 3 espécies estudadas, seguiu a mesma tendência observada nas cascas, ou seja menores concentrações de $\mathrm{P}$ foram observadas no lenho da porção basal dos caules do que nos lenhos da porção apical conforme FIGURA 3. As médias dos teores de P entre Neea macrophylla e Cecropia palmata não diferiram significativamente nas 3 porções do lenho considerada, indicando que o uso de material lenhoso dessas espécies como mulch também pode ser recomendável no aumento dos níveis de $\mathrm{P}$ nos solos da região, sobretudo quando se analisa os estoques de P. Mais uma vez Casearia arborea acumulou quantidades muito baixas de $\mathrm{P}$ nas 3 porções do lenho em relação às outras 2 espécies. Sendo assim, se fossemos utilizar o Teor de $\mathrm{P}$ total nos tecidos foliares e lenhosos como parâmetro de seleção de recursos vegetais potencialmente acumuladores de $\mathrm{P}$ para produção de mulch rico em P, os tecidos foliares de Neea macrophylla e Cecropia palmata poderiam exercer esta função sobretudo em ambientes deficientes em P. Porém, o Teor de P nas cascas e nos lenhos, por terem sido muito baixo para todas as espécies, pouca modificação traria. 


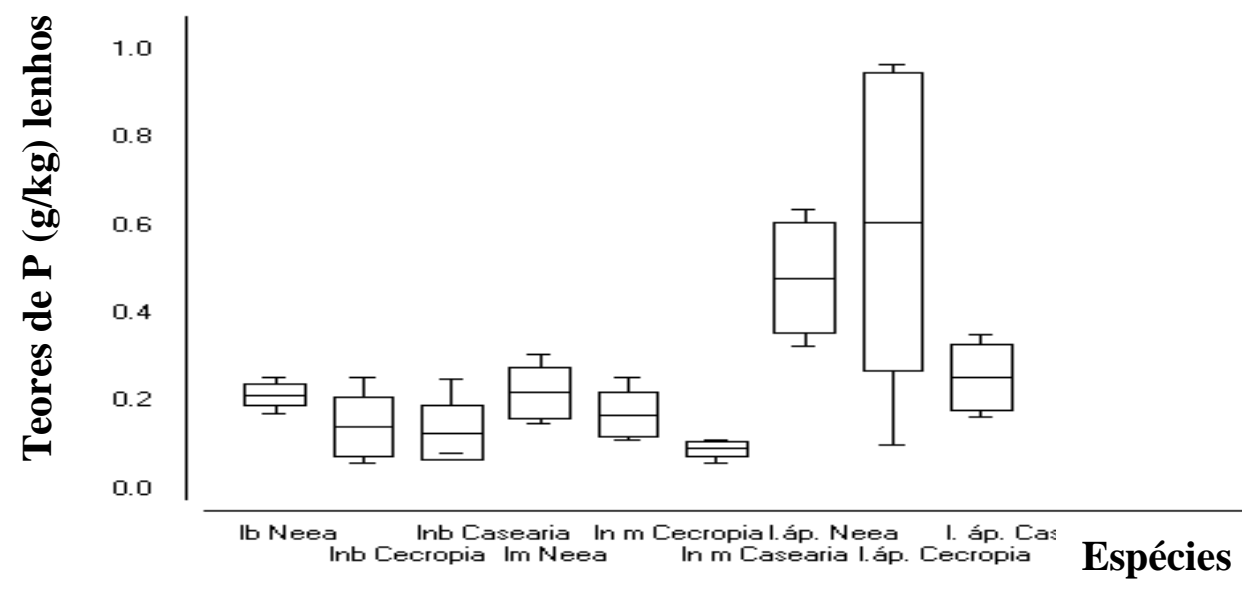

FIGURA 3 - Teores de P (g/kg na matéria seca) em lenhos das porções basal (lb), mediana (lm) e apical (l.áp.) dos caules primários de Neea macrophylla, Cecropia palmata e Casearia arborea com respectivos desvios padrões (box plot) e máximos e mínimos (suíças). *entre os lenhos do meio e do ápice de Neea e Cecropia e entre os lenhos da base de Cecropia e Casearia não houve diferenças significativas.

Contudo, quando avaliamos o estoque de $\mathrm{P}$ em folhas e lenhos primários de Neea macrophylla e Cecropia palmata (FIGURA 4) observamos que o compartimento lenho primário alcança valores muito próximos dos obtidos nas folhas, indicando estoques de $\mathrm{P}$ na ordem de $0.9 \mathrm{~kg}$ de $\mathrm{P}$ em folhas de 1 árvore de Neea macrophylla e de até $1 \mathrm{~kg}$ de $\mathrm{P}$ no lenho primário. As 2 espécies potencialmente acumuladoras de $\mathrm{P}$, Neea e Cecropia apresentaram padrões muito semelhantes quanto ao particionamento de $\mathrm{P}$ não diferindo significativamente. Dessa forma, quando utilizamos o parâmetro Estoque de $\mathrm{P}$ para seleção de espécies potencialmente acumuladoras deste elemento, podemos sugerir que além do tecido foliar, o tecido lenhoso de Neea e Cecropia estocam quantidades significativas deste elemento, resultado este que amplia de certa forma as opções de utilização das espécies aqui selecionadas, ao contrário do parâmetro de avaliação Teor de $\mathrm{P}$ nos tecidos, que não levando em consideração a produção de biomassa por compartimento acaba por minimizar a importância de compartimentos de estoque de $\mathrm{P}$ como as cascas dos caules primários. Entretanto a produção contínua de folhas ao longo do ano é muito mais interessante para obtenção de liteira rica em $\mathrm{P}$ do que o corte definitivo das árvores, pois introduzindo recursos vegetais perenes com função ecológica restauradora dos níveis de $\mathrm{P}$ em solos deficientes como os dos Sistemas Agrícolas locais, onde a lavoura branca predomina e com ela suas culturas de ciclo de vida curta terão uma alternativa para a restauração da sustentabilidade de ambientes impactados. 


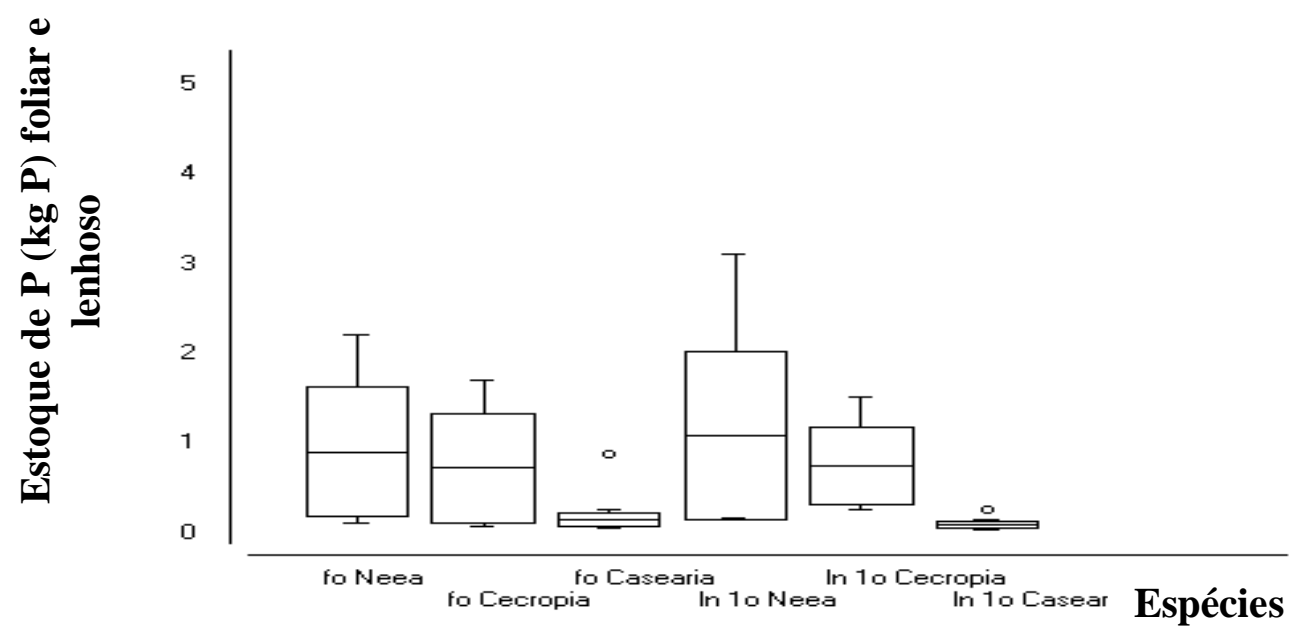

FIGURA 4 - Estoque de $\mathrm{P}$ (kg P na matéria seca) em folhas e lenhos primários de Neea macrophylla, Cecropia palmata e Casearia arborea com respectivos desvios padrões (box plot) e máximos e mínimos (suíças).* apenas entre as folhas de Neea e Cecropia e os lenhos das mesmas não houve diferenças significativas.

Se Neea macrophylla e Cecropia palmata apresentaram os maiores teores de $\mathrm{P}$ nas folhas do que Casearia arborea e melhor estocaram $\mathrm{P}$ nas folhas e nos lenhos primários, quem deveria ser mais Eficiente na Utilização do P? Os resultados demonstraram que a EUP pelas folhas das 3 espécies foi muito baixa, em torno de 0.10 a 0.57 , sendo os lenhos primários muito mais eficientes, onde Neea macrophylla obteve eficiência igual a 11.2 e Cecropia palmata 7.3 (FIGURA 5).

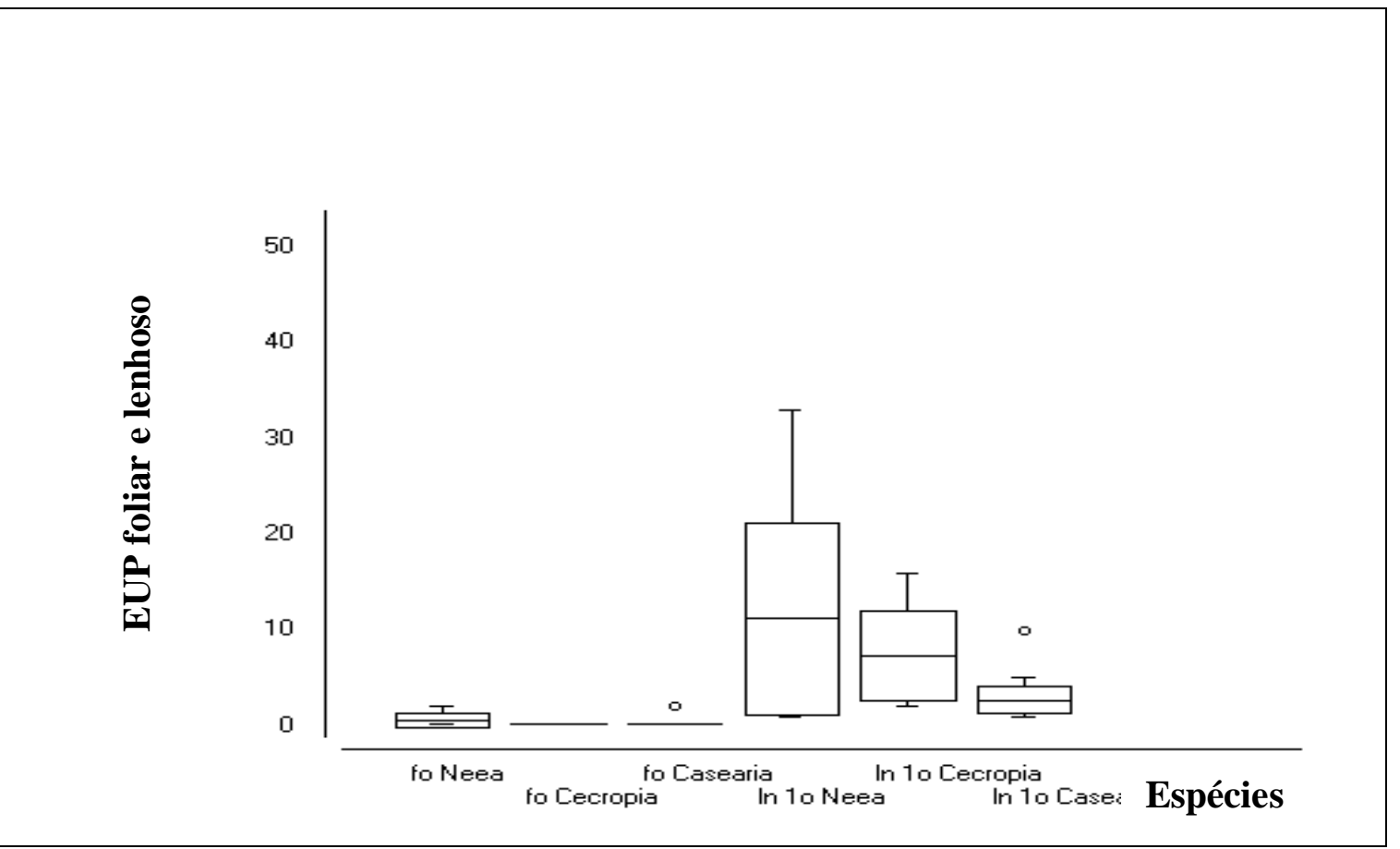

FIGURA 5- Eficiência de Utilização de P (EUP) em folhas (fo) e lenhos primários (ln) de Neea macrophylla, Cecropia palmata e Casearia arborea com respectivos desvios padrões (box plot) e máximos e mínimos (suíças). 
Em termos de EUP total Neea macrophylla foi a espécie mais eficiente na utilização de $\mathrm{P}$ (FIGURA 6), diferindo significativamente ao nível de $5 \%$ de probabilidade de Casearia, mas não de Cecropia. Estes resultados indicam que de forma geral as espécies são pouco eficientes na utilização do $\mathrm{P}$, tanto as com potencial para acumular, como Neea e Cecropia quanto as que não possuem este potencial, como Casearia, sobretudo quando comparamos com a EUP em espécies florestais do cerrado como Aroeirinha, Paineira e Jambolão submetidos a diferentes doses de P (Fernandes et al, 2000). Entretanto a baixa EUP total pelas espécies aqui estudadas é per se uma estratégia de sobrevivência das mesmas pois a tendência de se reduzir a Produção de Biomassa ou reduzir os Teores de $\mathrm{P}$ nos tecidos culminado com baixas EUP permite o crescimento dessas árvores em condições nutricionais tão deficientes. É importante destacar o metabolismo fantástico que deve ocorrer no lenho em função dos estoques de $\mathrm{P}$ significativos encontrados, estando de acordo com o trabalho de Mimura et al (1996), onde em situações de estresse o P é estocado no Caule, e que provavelmente pode estar associado à quebra de $\mathrm{P}$ orgânico de folhas mais velhas também.

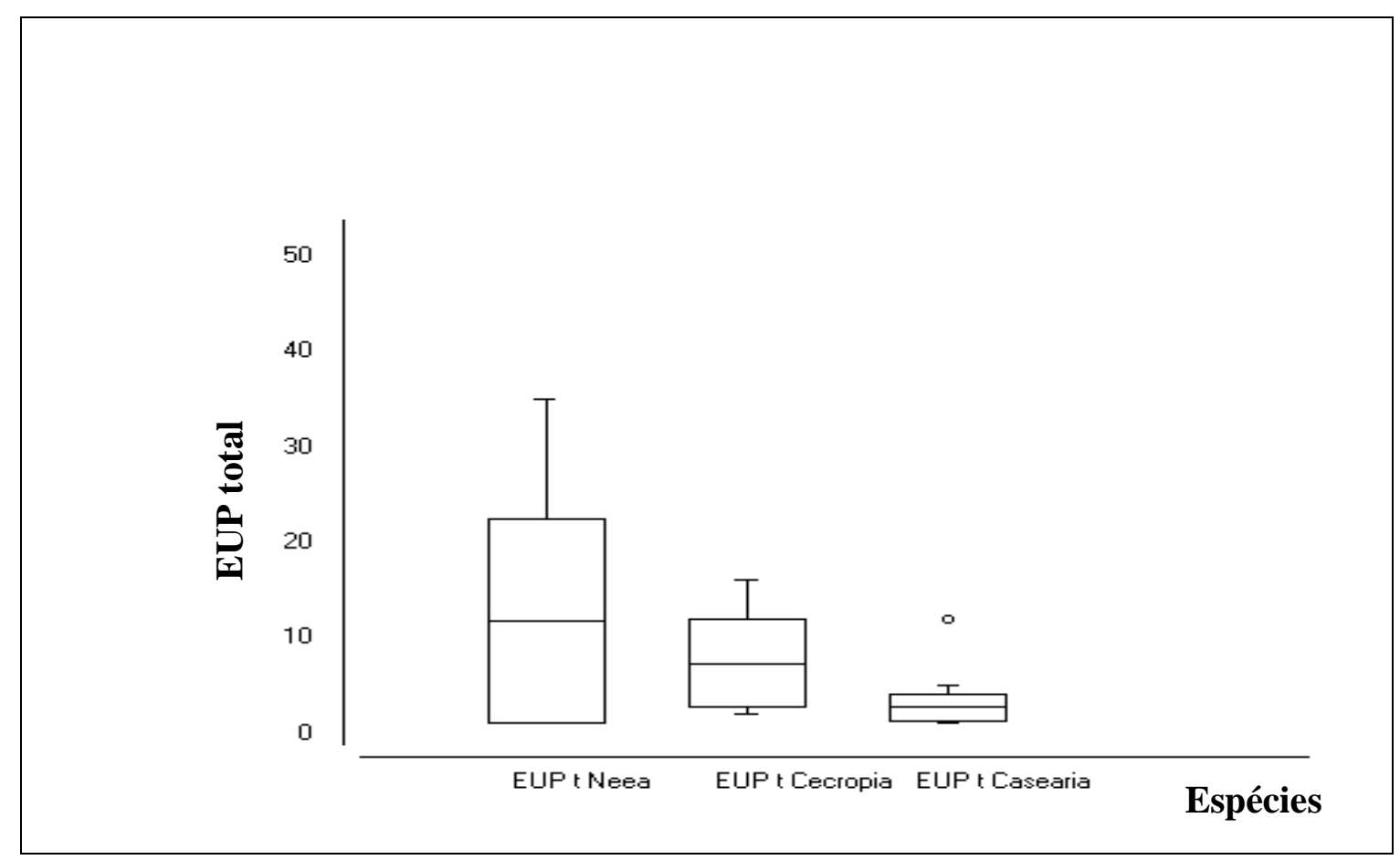

FIGURA 6- Eficiência de Utilização de P total (EUP $)_{\mathrm{t}}$ em Neea macrophylla, Cecropia palmata e Casearia arborea com respectivos desvios padrões (box plot) e máximos e mínimos (suíças).

Quanto ao particionamento do Teor de $\mathrm{N}-\mathrm{NH}_{4}$ pelos sete compartimentos estudados observamos que ele encontra-se em maior concentração nas folhas do que nas cascas e lenhos, sendo Neea macrophylla a espécie com maior Teor conforme FIGURA 7. A mesma dinâmica observada quanto ao $\mathrm{P}$ foi notada quanto ao $\mathrm{N}$, isto é existe um aumento crescente dos Teores de $\mathrm{N}_{-} \mathrm{NH}_{4}$ nas cascas e lenhos da base para o ápice evidenciando um dreno significativo na região apical dos caules nas três espécies estudadas. 


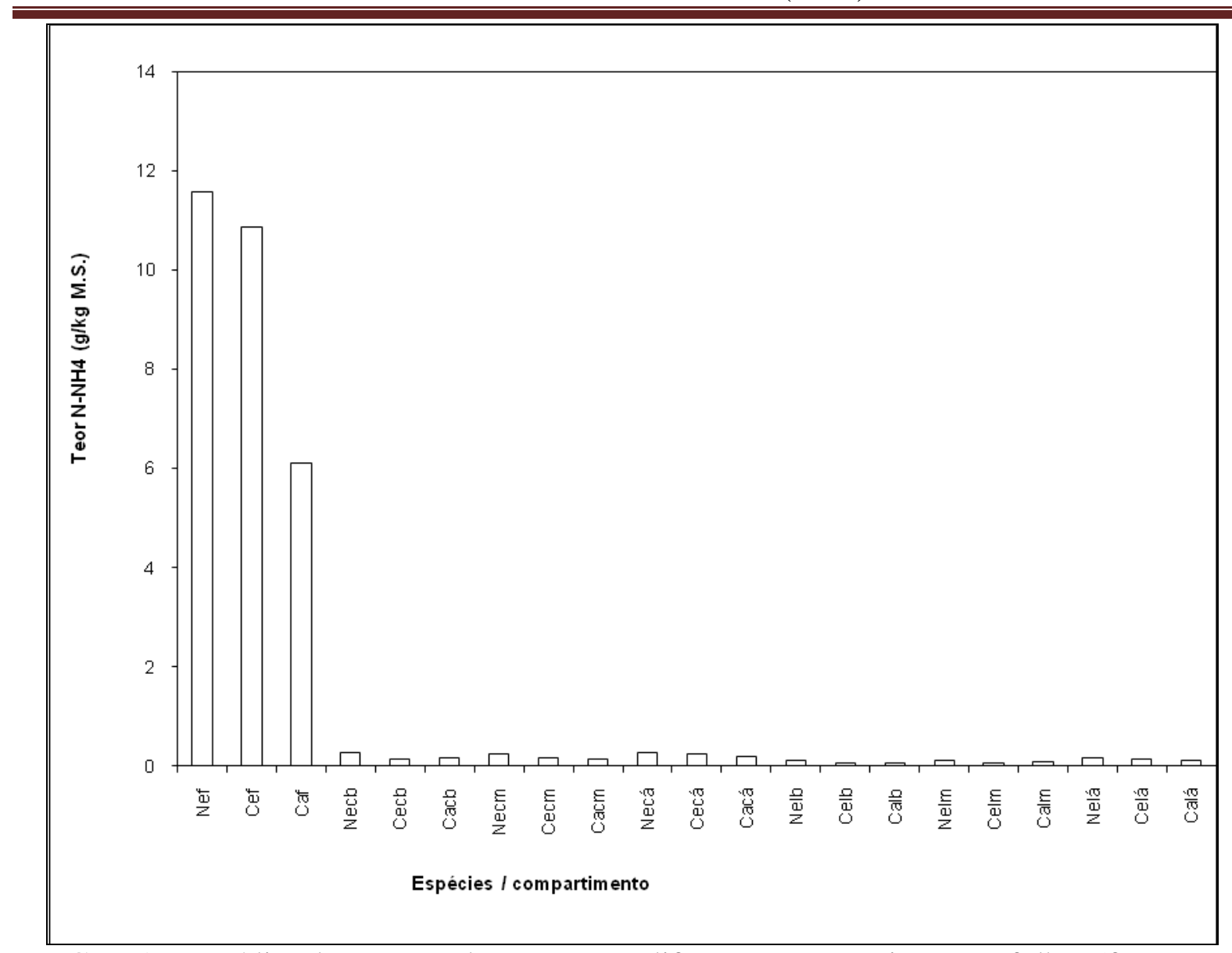

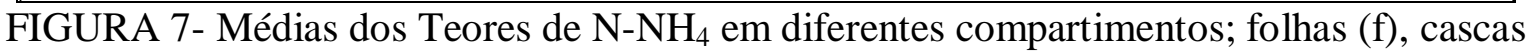
da porção basal do caule $(\mathrm{cb})$, da porção mediana $(\mathrm{cm})$, da porção apical (cá), lenhos da porção basal (lb), da porção mediana $(\mathrm{lm})$, da porção apical (lá) em duas espécies acumuladoras de $\mathrm{P}$, Neea macrophylla $(\mathrm{Ne})$ e Cecropia palmata $(\mathrm{Ce})$ e em uma não acumuladora, Casearia arborea $(\mathrm{Ca})$.

As análises Multivariadas mostraram diferenças estatísticas entre as espécies a partir do conjunto das sete variáveis analisadas ou compartimentos de acordo com a TABELA 1. Considerando os 3 parâmetros estudados, Teor, Estoque e EUP, podemos observar que as baixas EUP pelas espécies potencialmente acumuladoras não determinam menor tolerância das espécies a condições de déficit do nutriente no solo, mas sim um mecanismo de defesa frente a situações adversas de fertilidade onde a baixa produção de biomassa se faz necessária. 
Tabela 1- Análises Multivariada a partir da aplicação do Teste de Hotteling para comparação dos teores de $\mathrm{N}_{-} \mathrm{NH}_{4}$ em sete compartimentos ou variáveis (var 1- folhas, var 2cascas da base do caule, var 3 - cascas do meio, var 4- cascas do ápice, var 5- lenhos da base, var 6- lenhos do meio, var 7- lenhos do ápice) entre Neea macrophylla e Cecropia palmata,

NeeaXCasearia e CecropiaXCasearia.

\begin{tabular}{|c|c|c|c|c|c|c|c|}
\hline Neea X Cecropia & Var 1 & Var 2 & Var 3 & Var 4 & Var 5 & $\operatorname{Var} 6$ & Var 7 \\
\hline Amostra 1: Neea & 11.591 & 0.2767 & 0.2472 & 0.2842 & 0.1264 & 0.1059 & 0.1677 \\
\hline Amostra 2: Cecropia & 10.870 & 0.1361 & 0.1743 & 0.2608 & 0.0703 & 0.0748 & 0.1311 \\
\hline$(p)=$ & 0 & --- & --- & --- & --- & --- & --- \\
\hline \begin{tabular}{|l} 
Neea X \\
Casearia
\end{tabular} & & --- & --- & --- & --- & --- & --- \\
\hline Amostra 1:Neea & 11.591 & 0.2767 & 0.2472 & 0.2842 & 0.1264 & 0.1059 & --- \\
\hline Amostra 2:Casearia & 6.106 & 0.1654 & 0.1529 & 0.1951 & 0.0733 & 0.077 & 0.0006 \\
\hline$(p)=$ & 0 & --- & --- & --- & --- & --- & --- \\
\hline $\begin{array}{l}\text { CecropiaX } \\
\text { Casearia }\end{array}$ & & & & & & & --- \\
\hline Amostra 1:Cecropia & 10.870 & 0.1361 & 0.1743 & 0.2608 & 0.0703 & 0.0748 & 0.1311 \\
\hline Amostra 2:Casearia & 6.106 & 0.1654 & 0.1529 & 0.1951 & 0.0733 & 0.07 & 0.111 \\
\hline$(p)=$ & 0.0001 & -- & & & & & \\
\hline
\end{tabular}

\section{CONCLUSÕES}

Neea macrophylla e Cecropia palmata demonstraram ser recursos vegetais potencialmente acumuladores de fósforo, sobretudo as folhas, embora os tecidos lenhosos tenham melhor estocado, logo a liteira e o mulch foliar e lenhoso dessas espécies pode vir a ser útil na restauração dos níveis de $\mathrm{P}$ dos solos submetidos à Agricultura Itinerante. A Eficiência de Utilização de $\mathrm{P}$ pelas folhas dessas espécies foi muito baixa, ou seja, a conversão em biomassa foliar foi baixa sugerindo que embora a liteira seja rica em $\mathrm{P}$, as quantidades desse material não são tão significativas. A expressiva EUP pelos lenhos de espécies potencialmente acumuladoras de P como Neea macrophylla e Cecropia palmata sugere maior viabilidade na utilização da liteira e do mulch lenhoso e, por conseguinte a derruba de árvores ou podas sistemáticas poderiam ser uma boa intervenção para a recuperação dos níveis de $\mathrm{P}$ em Sistemas Agrícolas locais a partir de plantios sistemáticos dessas espécies quando uma vez domesticadas. Neea macrophylla devido às maiores concentrações de $\mathrm{N}^{-\mathrm{NH}_{4}}$ encontradas parece oferecer condições melhores ao processo fotossintético.

\section{REFERÊNCIAS}

1. AYRES, M.; AYRES JUNIOR, AYRES, D.L. \& DOS SANTOS, A .S BioEstat 3.0. Aplicações estatísticas nas áreas das Ciências Biológicas e Médicas. Sociedade Civil Mamirauá/MCT-CNPQ/ Conservation Internacional, Belém, Pará, 2003.

2. BRemner, J. M., AND C. A. MUlvaney Total nitrogen. In A. L. Page, R. H. Miller and D. R.Kenney, editors. Methods of soil analysis. Part 2 (Agronomy Monographs 9). American Society of Agronomy, Madison, Wisconsin, USA, pp595624,1982 
3. CHERBUY, B., JOFFRE R., GILLON, D. E RAMBAL, S. Internal remobilization of carbohydrates, lipids, nitrogen and phosphorus in the Mediterranean evergreen and oak Quercus ilex. Tree Physiology, Canadá, 21: 9 - 172001.

4. FERNANDES, L. A., FURTINI NETO, A, FONSECA, F.C. E VALE, F. R. Crescimento inicial, níveis críticos de fósforo e frações fosfatadas em espécies florestais. Pesq. Agropec. Bras., Brasília, 35: 6, 2000.

5. P. MEIR, J. GRACE \& A. C. MIRANDA- Leaf respiration in two tropical rainforests: constraints on physiology by phosphorus, nitrogen and temperature. Functional Ecology, 15, 378-387, 2001.

6. MIMURA, T.; SAKANO, K. E SHIMMEN T. Studies on the distribution, retranslocation and homeostasis of inorganic phosphate in barley leaves. Plant Cell Environment, 19:311-320, 1996.

7. MURPHY, J. \& RILEY, J.P.- A modified single solution method for the determination of phosphate in natural waters. Anal. Chim. Acta. 27;31-36, 1962.

8. OLIVEIRA, P.C.; CARVALHO, C.J.R.; SÁ, T.D.A .E BRIENZA, S.- Prospecção de espécies vegetais potencialmente acumuladoras de $P$ : uma estratégia para a melhoria de sistemas agroflorestais seqüenciais no nordeste Paraense. ANAIS do $4^{\mathrm{o}}$ Congresso Brasileiro de Sistemas Agroflorestais, Ilhéus, Bahia, 2002.

9. PARKS, S.E., HAIGH, A.M. E CRESSWELL, G.C. Stem tissue phosphorus as an index of the phosphorus status of Banksia ericifolia L. f. Plant and Soil, 227: 1-2, pp. 59-65, 2000.

10. SIDDIQI, M. Y.; GLASS, A .D.M. - Utilization index: a modified approach to the estimation and comparison of nutrient utilization efficiency in plants. Journal of Plant Nutrition, New York, v.4, p.289-330, 1981.

11. SMITH, K.T. E SHORTLE,W.C. Conservation of element concentration in xylem sap of red spruce. Springer - Verlag, 2001.

12. VANCE, C.P. Symbiotic Nitrogen Fixation and Phosphorus Acquisition. Plant Nutrition in a World of Declining Renewable Resources. Plant Physiol., 127: 390397, 2001.

13. WATSON, L. \& DALlWITZ, M.J. The Families of Flowering Plants, $14^{\mathrm{a}}$ edição, 2000. 